\title{
Tattoo: \\ a multifaceted medium of communication
}

\section{Christian Wymann}

MedieKultur 2010, 49, 41-54

Published by SMID | Society of Media researchers In Denmark | www.smid.dk The online version of this text can be found open access at www.mediekultur.dk

This article suggests the systems theoretical distinction of form/medium as a useful tool for distinguishing social phenomena that might look as if they stem from the same process. This is shown to be the case for the tattoo and tattooing. The tattoo is conceived as a medium of communication through which different forms of communication emerge. Tattooing is one of these forms of communication that shapes the medium in a particular way. The current article sheds a special light on its intricate, communicational constellation, for which the concept of parallax is suggested. Law, medicine and cosmetics as other forms of communication use the medium of tattoo in their own way as well. The form/medium distinction allows us to grasp these different forms of communication, while it shows that they share the tattoo as medium. The article's ultimate goal is to illustrate that the tattoo figures as a multifaceted medium of communication.

\section{Introduction}

On the surface, certain social phenomena seem to share many characteristics because of their similar appearances or comparable constellations of people involved. In everyday accounts, such phenomena may be described in the same terms without necessarily dwelling on their differences. Academic studies, in contrast, suggest ways and criteria to understand and distinguish between phenomena. Depending on the definition, different aspects 
of the phenomena come into view, making visible some of the features they share and others that differ. While every definition inevitably includes and excludes certain aspects, some are scientifically more useful than others. With definitions that are too general and imprecise, phenomena may appear quite similar. With a more concise but nevertheless sufficiently abstract definition, one can see more clearly both similarities and differences of phenomena that are usually lumped together indiscriminately.

In examining tattooing and tattoos, this article suggests defining the phenomena in a new way by distinguishing between form and medium. This allows one to grasp the particular communicational characteristics of tattooing and tattoos and see how they make a difference socially. In the end, one not only gets a clear definition of what tattooing is and how it works in terms of communication: the use of the form/medium distinction also helps to distinguish tattooing from phenomena that are commonly subsumed under the same term, yet work in a different way.

The distinction between form and medium, taken from Niklas Luhmann's systems theory, constitutes one of the main conceptual tools for investigating the social character of tattooing and tattoos. Luhmann developed a theory of society as a social system constituted by communication in its different forms and media (Luhmann, 2001). Focusing on modern society and its differentiation into functional systems, such as, economy, art, science, politics, law and others (subsystems of society), Luhmann's work analyses the particular (symbolically generalised) media and forms (codes) of these systems' communication (e.g., Luhmann 1996, 2000, 2002). Even though they all are comparable in some respects (i.e., functionally equivalent), each functional system works in its own special manner. As a result, the forms of communication (operations) responsible for the systems' constitution remain incommensurable with one another. As Luhmann's work exemplifies, the form/ medium distinction provides an abstract tool that helps to grasp diverse phenomena in terms of communication and to compare them. Ultimately, systems theory provides the theoretical tools for understanding social phenomena like tattooing and tattoos in their own terms. Instead of exclusively looking at what people do or say, it enables a direct focus on the communicational specifics of a phenomenon.

On the one hand, the form/medium distinction prompts the question of which form of communication tattooing features. On the other, the researcher must clarify in which medium (or media) this form operates. As will be made clear, tattooing constitutes a rather peculiar form of communication. ${ }^{2}$ Tattooing not only includes economy and art as forms of communication, but also operates through several media. In order to grasp this particular communicational constellation of forms and media, I suggest we "poach" outside of systems theory. ${ }^{3}$ Specifically, I argue that the concept of parallax (Žižek, 2004, 2006) may help to specify this particular form.

With a fresh perspective on the tattoo as a multifaceted medium of communication and tattooing as a social phenomenon, I first want to contribute to a more precise and consistent conceptualisation of the two. Secondly, I want to demonstrate how the form/ 
medium distinction may contribute to a better and more differentiated understanding of social phenomena in general.

In the first section, I discuss common definitions of tattooing in academic literature in light of concrete cases. Further, I want to show how a concept of tattooing in terms of form and medium contributes to a new understanding of the social phenomenon. In a third step then, I suggest a conceptualisation of tattooing as a particular form of communication within its specific media. Finally, I return to the cases initially presented in order to re-emphasise the malleability of the tattoo as a medium.

\section{Common definitions of tattooing}

Social scientists from different disciplines have studied tattooing since the 1980s, looking at the phenomenon from a variety of angles (e.g., Sanders, 1989; Gell, 1993; DeMello, 2000; Sullivan, 2001; Atkinson, 2003; Fenske, 2007). The different theoretical frameworks, sources of empirical data and types of analyses produce a rich picture of the phenomenon. The studies consider a wide range of topics: the motivations of the people getting tattooed; the formation of groups on the basis of tattoos; the wider social or cultural context in which tattoos appear; the workings of tattoo establishments and the organisation of creating tattoos; and the public display and evaluation at tattoo conventions and by the mass media (tattoo magazines, television shows and the press). Other disciplines such as psychology, criminology and medicine cover many additional topics.

Despite their empirical richness and theoretical variety, these studies only seldom provide explicit specifications of the basic phenomena involved. As I want to show briefly, the suggested definitions are not clear or distinct enough to specify the social character of tattooing and tattoos. In particular, the common definitions of tattooing are not able to distinguish it from phenomena with a similar appearance that work in different ways. Rather, differences between them disappear while the phenomena are lumped together.

The literature provides three prevalent modes of defining tattooing. We will call them technical-material definitions, definitions of effect and social definitions. Often, several of these definitions appear in one and the same study, i.e., they are not necessarily mutually exclusive. First, technical-material definitions specify tattooing in regard to tools, materials and procedures. "The defining feature of tattooing", Gell (1993, p. 38) writes, "is that it is the making of indelible pigmented traces which are inside or underneath the skin". DeMello (2007, p. 265) defines it in similar terms, additionally referring to the tools used and "a decorative design" as the outcome. Second, definitions of effect specify tattooing as the alteration of the body. They focus on the outcome of the technical-material procedure. "Body modification" and "body alteration" are two commonly used phrases for characterising tattooing (e.g., Pitts, 1999). This definition compares and contrasts tattooing to other forms of body modification, such as piercing, branding, plastic surgery, haircutting and cosmetics (see Myers, 1992; Featherstone, 1999). Forms of body modification are divided into catego- 
ries such as permanent/temporary, voluntary/enforced, deviant/mainstream and radical/ moderate (see Sanders, 1989; Myers, 1992; DeMello, 2000; Atkinson, 2003; Pitts, 2003). The third type of definition specifies tattooing explicitly in social terms. The notion of practice, for example, is widely used in the context of different theoretical frameworks. Other concepts for tattooing such as social behaviour or activity, body project and others are often used (see Sanders, 1989; Blanchard, 1991; Gell, 1993; Sullivan, 2001; Atkinson, 2003). Those who draw on a Foucauldian framework define tattooing also as a form or "technology" of subjectivisation (Gell, 1993; Benson, 2000; Sullivan, 2001). Except for the latter conceptualisations, social definitions tend to remain rather implicit and are presented as self-evident.

As indicated, one of the main problems I see with these definitions is that they lump together what might make a difference in society. Take the following cases that are commonly described as tattooing: the creation of designs by a tattooist for a customer in a tattoo shop; the inscription of symbols for the marking and punishment of criminals (see Gustafson, 2000; Jones, 2000; van Gulik, 1982); the medical reconstruction of skin features; and the permanent cosmetic beautification of facial features (Vassileva \& Hristakieva, 2007). A technical-material definition would see tattooing in each case, because they all have in common the tools, materials and procedures for inserting ink. Similarly, definitions concentrating on the outcome would treat all cases as tattooing because they involve body modification. The only distinctions these definitions could make would be the mentioned subcategories. Accordingly, the cases would be described as voluntary, enforced or permanent body modifications, depending on their contextualisation. Social definitions such as the concept of practice would see all of them as tattooing as well (see, e.g., Sanders, 1989). The rather vague social definitions would not see fundamental differences, since tattooing is basically a social act or a practice done by people (sometimes implicitly attributed to both the person doing it and the one getting it done; see Atkinson, 2003).

In general, these definitions are all too ready to define various phenomena as tattooing and neglect the context in which they take place. This does not mean, however, that one has to assume a priori differences between the different cases. Instead, I propose focusing on the specific features that set them apart. The form/medium distinction serves this purpose. Even though the tattoo figures as the medium that is common to all the cases, the forms of communication differ from each other. The form/medium distinction provides insight into both the commonalities and differences of various phenomena.

\section{The form/medium distinction}

I propose using the distinction of form and medium (Luhmann, 1987) to grasp the phenomenon of tattooing. A medium is defined as loosely coupled elements, and the form, correspondingly, as a strict coupling of these elements. A medium is equipped with "a very high degree of dissolution" (Luhmann, 1987, p. 101) that makes it receptive to formation. These loosely coupled elements constitute a medium substrate through which forms emerge (e.g., 
sound as the form in the medium of air; communication and consciousness as different forms in the medium of meaning; Luhmann, 2001). The medium itself does not predetermine its formation. A form, then, shapes a medium in keeping with its own particular mode without destroying or taking away the characteristics of the medium. As Luhmann (1987, p. 102) puts it, the form selects "from the possibilities offered by a medium". If a form stops to draw on a medium, another form can potentially use the same medium.

The concept of form has yet another, complementary meaning. It refers to a distinction with two sides (e.g., payment/non-payment; Luhmann, 1999; Spencer-Brown, 1999). However, only one of them is usually indicated (marked). The other side is unmarked, even though it remains constitutive for the form (e.g., payment as the marked side of the economic code payment/non-payment). This unmarked side as well as the observer (e.g., a functional system) that draws the distinction remain in the "blind spot" of the form. In general, this applies to every form.

The distinction of form/medium allows for a definition of tattooing as a form of communication that operates through its own specific medium (or media, as will be shown). Instead of asking what tattooing is in terms of the materials used or who is doing the tattooing, I suggest that one should focus on how tattooing communicates. Unlike the common definitions of tattooing, such a focus allows for an analytical distinction between phenomena that appear similar on the surface. Upon closer inspection, it becomes possible to discern the forms and media that constitute the phenomenon. Eventually, apparent similarities between phenomena turn into differences in the way they communicate. One gains insights that existing definitions of tattooing are unlikely to provide.

\section{Parallactic form of tattooing and its media}

Both everyday and academic accounts recurrently describe tattooing and tattoos in terms of business, service, industry, consumer product, art form, creativity and the like (e.g., Govenar, 2003; Sanders, 1989; Blanchard, 1991; Atkinson, 2003; Grandy \& Wicks, 2008). There is no doubt that art and economy play an important role in the constitution of tattooing. Both academic descriptions and everyday accounts take the economic and artistic aspects of tattooing and tattoos for granted. In academic accounts, economy and art are rarely substantiated theoretically. This applies even more to potential relations between them (see, e.g., Blanchard, 1991, p. 14; Atkinson, 2003, p. 47). Academic descriptions in terms of art and economy are certainly not wrong in drawing on this ubiquitously used semantics. However, one needs to conceive both of them in a more theoretically grounded way in order to understand the role they play for tattooing and tattoos. ${ }^{4}$

Instead of switching between descriptions of tattooing in terms of economy and art, I want to argue for a different approach. Economy and art, I suggest, contribute equally and in close connection to each other to the constitution of tattooing as a social phenomenon. The question of how economy and art each contribute to tattooing, on the one hand, and 
how they relate to each other, on the other, can be elaborated in particular by drawing on the distinction of form and medium. For the purpose of an empirically more adequate concept of tattooing, however, one needs to slightly modify the concept of form. Here, then, the concept of parallax comes into play. Let me first present the form of tattooing and its particularity. Then, I address the role of the tattoo as a medium.

The particularity of tattooing as a form of communication is due to three features. First, tattooing unites two forms, namely economic and artistic communication. Even though they constitute operating forms of their own, they represent the two sides of the form of tattooing. Despite being "shaped" in the same form, however, economy and art do not surrender their distinctiveness. Due to their different modes of operation, they remain incommensurable with each other (but nevertheless "compossible", Fuchs, 1992, p. 109). In this case, together they constitute the form of tattooing as an operation of its own.

Second, economy and art function as equally constitutive parts of tattooing. Neither of them takes priority. Rather, they both constitute tattooing in a parallel and closely coupled manner. Because of this parallel and equal involvement of art and economy, tattooing differs from other forms of communication. Unlike the codes of functional systems, the form of tattooing does not work according to the distinctions of designation/reflection, positive/ negative values or manifest/latent (Luhmann, 2001, p. 363, 2008, p. 70). It always designates, so to speak, both sides, by which they both become positive and manifest (with that, however, these terms lose their meaning). In order to grasp this special constellation of artistic and economic communication, one needs an additional concept for its characterisation. For this purpose, I use the concept of parallax, which is inspired by the work of Slavoj Žižek (2006). ${ }^{5}$

According to Žižek, the "parallax view" refers to "the apparent displacement of an object (the shift of its position against a background), caused by a change in observational position that provides a new line of sight" (2006, p. 17). To this common definition (see Ginsburg, 1995), Žižek adds a "philosophical twist". He argues "that the observed difference is not simply 'subjective', due to the fact that the same object which exists 'out there' is seen from two different stances, or points of view" (p. 17). Rather, Žižek states in Hegelian terms: "subject and object are inherently 'mediated', so that an 'epistemological' shift in the subject's point of view always reflects an 'ontological' shift in the object itself" (p. 17). Such shifts occur in objects that imply different and incommensurable perspectives. In order to understand this object, the observer has to oscillate between the perspectives involved. The incommensurability or "irreducible asymmetry" (Žižek, 2006, p. 29) of the perspectives precludes a reduction to solely one of them or their blending (Žižek, 2004).

In order to incorporate the concept of parallax into systems theory, one can frame it in terms of observation (on observation, see Luhmann, 1995). The concept of parallax basically implies that an "object" or social phenomenon will look different depending on the observer's point of observation or his criteria for drawing a distinction. The phenomenon "out there", as Žižek's philosophical twist adds, is always also the construction of an obser- 
vation. Because it emphasises observer dependence, the concept of parallax is connectable and compatible with the concept of observation.

As stated above, tattooing unites two incommensurable forms of communication. In terms of Žižek's position, its reduction to economy or art only or their blending is not possible (even if both of them consist of communication). Economy and art both deal with tattooing in different but connected ways. Each of them can be seen as a different observer that uses an individual set of distinctions (basically the codes of the function systems). In this sense, tattooing does not represent "an object out there" but is the result of the closely linked actualisation of economic and artistic communication. From the point of view of economy the phenomenon appears different than from the perspective of art. In order to understand how tattooing works as a form of communication, both perspectives need to be taken into account.

By defining tattooing as a parallactic form of communication, I want to draw attention to this particular arrangement of two incommensurable forms of communication under one form. Despite their irreducibility, economy and art figure as co-constitutive facets of tattooing.

The third particular aspect of tattooing concerns the medium through which it communicates. A form depends on a medium in order to emerge. As Luhmann (1987, p. 103) points out, " $[t]$ here is neither a medium without form nor a form without medium". Due to its constitution by both economic and artistic communication, tattooing basically communicates through their corresponding symbolically generalised communication media. Economic communication works through the media of money and possessions (Luhmann, 1996). Art, by contrast, communicates by means of artworks (i.e., arrangements of decisions of form; Luhmann, 1987, 2000). In addition, tattooing is equipped with its own specific medium that brings art and economy closely together. The tattoo figures as such a medium for both forms of communication. On the one hand, it constitutes the commodity exchanged in an economic transaction. On the other hand, it represents what is created by art. The tattoo, thus, constitutes the medium of the parallactic form because it figures simultaneously as that which is created and exchanged in one and the same communicational event.

The tattoo as medium could in turn be broken down into its components. One would see an entire cascade of form/medium distinctions, each of them again constituting a medium for a higher-level form/medium distinction (light, biological cells, pigments; then colour, skin, ink; then lines and patterns inserted into the skin; then particular designs of different sorts). These lower-level form/medium distinctions, however, figure more in a yet "pre-communicational" manner relative to the tattoo as a medium. Only the tattoo emerges as a medium on which forms of communication can draw.

These three features, the parallelism of two incommensurable forms of communication, their combination in a parallactic form, and the medium of tattoo, constitute together the particular form of tattooing. 


\section{Communicating through the medium of tattoo}

Although art and economy possess their own specific media, the tattoo partly assumes their roles. The tattoo functions both as a commodity to be exchanged and a work of art.

A variety of parameters structure how tattooists and customers interact and how a tattoo organisation contextualises this interaction (I cannot address the differences in expectations, interactions and organisational decisions here; see, e.g., Sanders, 1989). Regardless of these variations, tattooing as a form of communication either takes place or not. The form of tattooing implies that it only occurs if communication operates according to its form. That is, only if both economic and artistic communication operate in the constellation described above does tattooing emerge.

From the economic point of view, the production of a tattoo happens in exchange for a payment. Both tattooist and (prospective) customer expect one another to have more or less the same basic expectations about the ensuing interaction. The tattooist expects the customer to choose freely to be tattooed, to choose a design, and to pay for getting the requested tattoo design. The customer, in turn, expects to be able to choose the design and, as an expectation of the tattooist's expectations, to have to pay the tattooist for the tattoo being done. The making of a tattoo, thus, will necessitate a payment in return. This constitutes the double movement of economic transactions (Luhmann, 1996): in exchange for a payment, customers receive a tattoo of their liking.

On the one hand, economic communication takes place by means of the code payment/non-payment in the medium of money. Money here not only refers to money in the typical sense (cash, credit cards etc.), but also to other loosely coupled elements such as objects. Whether the tattooist expects 200 Euros or a case of beer and food as alternative currencies, these will constitute a payment. ${ }^{6}$ On the other hand, economic communication without something in return will not be complete. Here the tattoo comes into play as the exchanged product. In order to close the economic transaction, the second code of to have/not to have appears (Luhmann, 1996). Customers request to get a tattoo on their skin, which becomes their property. As a consequence, the economic transaction as a communicational event is concluded once both the payment and the exchange of a commodity or service have taken place.

In the transaction, the tattoo emerges as the transacted and paid for commodity. At the same time, though, economic communication relies on the tattoo's emergence as a product of artistic communication.? From the perspective of artistic communication, the emergence and use of tattoos proceed differently. Art operates in the medium of artworks and in the code of harmonious/non-harmonious (and not beautiful/ugly; Luhmann, 1987, 2000, p. 191; but see Luhmann, 1993). ${ }^{8}$ The artwork as medium consists of an arrangement of decisions of form (in/by means of lower-level media). Lines, shapes, shades, size, placement, symbolic and realist elements, for example, figure as decisions and fixations of form. Together they constitute arrangements that offer themselves to or provoke perception and, ultimately, their observation in communication (Luhmann, 
1985, p. 7). The tattoo thus constitutes not only an exchangeable commodity but also a work of art.

Tattoos, it seems, have a particular potential to provoke perception and, as a result, communication by triggering fascination or revulsion (Steward, 1990). Tattoos emerge through the creation of particular arrangements of decisions of forms. Often these arrangements are available and perceptible as designs or sketches on paper (a different form of artwork). So-called "flash sheets", invented in the beginning of the twentieth century, display several tattoo designs in order to allow the customer to see what can be done (see Govenar, 2003). Today, "flash" designs still provide the opportunity to simply choose a tattoo "from the wall" or from folders on display. If the designs are not already available, the customers are asked to describe their ideas and wishes for their tattoo to the tattooist. Unlike "flash" designs that can be reproduced repeatedly, these "custom" tattoos are meant to be unique and individual pieces of work. Whether a tattoo design stems from a template or is the result of a consultation meeting between tattooist and customer, it will eventually constitute an arrangement of decisions of form in the skin. And whether these arrangements form different styles such as a realistic portrait of a person, a simple black ornament ("tribals"), or an elaborate Japanese composition of carps, water and chrysanthemums, what matters in artistic communication is its processing of the distinction of harmonious/non-harmonious pertaining to the decisions of form. The tattoo as artwork, thus, constitutes the medium of art insofar as it presents itself as arrangements of decisions of form in skin without itself fixing its own concrete appearance.?

The tattoo as a work of art provokes its perception and processing in communication by offering typical and established decisions of form. That is, artistic communication has to form the medium in a manner that enables its perception and communication about it. Even if a tattoo is not successful in offering matching decisions of form, it nevertheless is observed in regard to art.

The German tattoo periodical TätowierMagazin provides an exemplary case for observing descriptions of non-harmonious tattoos. The magazine contains a column called "Cucumber of the Month" ("Gurke des Monats") dedicated to the critical discussion of "bad" tattoos. The column explicitly observes failed decisions of form. Be it the drawing of the lines, the shading, or the individual motifs in a tattoo, the column presents arguments about why the tattoos in question by and large fail (they are characterised as "bad", "ugly", "abominable", "slobber" and "accidents"). The reason why I refer to this column is that it shows the tattoo's potential to make itself conspicuous as a medium of art. Even though the tattoos discussed in the column apparently fail to present themselves as harmonious arrangements of forms, they nevertheless get attention and become the subject of art-oriented communication. As Luhmann suggests, "[f]ailed works of art are still works of art, if unsuccessful ones" (Luhmann, 2000, p. 194). It is significant, though, that these tattoos also give rise to observations about their prices. Usually, tattoo magazines rarely address or judge the price of tattoos. But in this column the discussed tattoos are apparently legiti- 
mately judged as often overpriced for what they represent. In this regard, the tattoo as a sold and paid for commodity comes into focus.

\section{A multifaceted medium of communication}

The tattoo turns out to be a medium for many forms of communication. It figures as the medium of both economy and art. In the special form of tattooing, characterised by the concept of parallax, the tattoo emerges as both artwork and commodity to be exchanged for monetary compensation. As a consequence, the occurrence of tattooing as a form of communication relies on the double function of the tattoo as medium. Only this double function makes it possible for economy and art to take place simultaneously in the intricate constellation of a parallactic form. And only then does tattooing emerge as communication.

The presented case shows how different forms of communication can access the tattoo as a medium. It offers loosely coupled elements that only become meaningful in a particular context of communication. The tattoo, however, does not offer itself only to economy and art, but to other forms of communication as well. As long as the medium's malleability is guaranteed, it can potentially emerge in diverse and incommensurable communicational contexts.

Let me come back once again to the various forms of "tattooing" introduced in the beginning of this article. With a focus on the tattoo as a medium and the forms of communication drawing on it, one gets a more differentiated picture. The making of tattoos as punishment constitutes a form of law enforcement. Legal communication uses the medium of tattoo for the purpose of marking, "branding" and stigmatising individuals as criminals. It clearly differs from tattooing in its way of communicating. Although working with the medium of tattoo as well, so-called medical "tattooing" does not represent tattooing in the sense discussed above. As in the previous case, an additional semantics describes the phenomenon in this medical context (micropigmentation, dermatography; Vassileva \& Hristakieva, 2007). The tattoo here is formed by medical communication as marks that are applied for reconstructive and diagnostic purposes (for the latter, see Bland, 2009). These marks are the means by which medicine tries to restore health. Reconstructive tattoos of particular skin or body areas (e.g., mamillas) will ideally not be identifiable as tattoos. And if such marks attracted attention, it seems rather unlikely they would be observed in the same way as other, non-medically applied ones (e.g., in regard to art). Similarly, the case of "permanent make-up" or cosmetic tattoos is not the result of tattooing as the kind of communication presented above. For example, cosmetic beautification of facial features shapes the tattoo as a medium in a yet different way. In contrast to medical applications, it does not try to cure, but to beautify and re-emphasise existing physical features (see Vassileva \& Hristakieva, 2007; Burchett, 1960, chapters 8 \& 9).

The tattoo as a medium of communication, thus, emerges through diverse forms. From 
the point of view of communication, it looks different in each case. It remains, however, an empirical question of how exactly the medium is formed and how, with its help, a difference in communication is produced.

\section{Conclusion}

The tattoo has been presented as the central, multifaceted medium of the form of communication called tattooing. Due to the particular, parallactic form of tattooing, the tattoo features both as a medium of economy and art. But, as the examples of tattoos as punishment, medicine and cosmetics show, the tattoo even plays a role in other forms of communication.

In contrast to the common definitions of tattooing used in academic literature, the use of the form/medium distinction allows for a determination of the specific communicational constellation of the phenomenon; and, equally important, for a comparison of its form with those of other phenomena that share the same basic medium.

A focus on form/medium distinctions, then, might prove helpful in order to determine the communicational aspects of a social phenomenon. An empirically grounded study equipped with the form/medium distinction sheds light on how a phenomenon functions specifically as communication and in which medium this occurs. At the same time, a comparison with other phenomena shows the form/medium distinctions they work with. Such an approach may provide new insights about how phenomena form part of society. Ultimately, as shown for tattooing, the study of various social phenomena might produce further insights into their particular characteristics as forms of communication. The "pure" form (e.g., codes of functional systems), then, would turn out as only one possible form among others such as the parallax.

\section{References}

Atkinson, M. (2003). Tattooed. The sociogenesis of a body art. Toronto: University of Toronto Press.

Benson, S. (2000). Inscriptions of the self: Reflections on tattooing and piercing in contemporary Euro-

America. In J. Caplan (Ed.), Written on the body. The tattoo in European and American history (pp. 234-254). London: Reaktion Books.

Blanchard, M. (1991). Post-bourgeois tattoo: Reflections on skin writing in late capitalist societies. Visual Anthropology Review, 7(2), 11-21.

Bland, Eric (2009). Nano ink 'tattoo' could monitor diabetes. Retrieved January 21 2010, from http://dsc. discovery.com/news/2009/02/12/diabetes-tattoo.html

Bohn, C. (2000). Kleidung als Kommunikationsmedium. Soziale Systeme, 6(1), 111-135.

Burchett, G. (1960 [1958]). Memoirs of a tattooist. From the notes, diaries and letters of the late 'King of Tattooists' (compiled and edited by Peter Leighton). London: Pan Books Ltd.

DeMello, M. (2000). Bodies of inscription. A cultural history of the modern tattoo community. Durham \& London: Duke University Press. 
DeMello, M. (2007). Encyclopedia of body adornment. Westport, Conn./London: Greenwood Press.

Featherstone, M. (1999). Body modification: An introduction. Body \& Society, 5(2-3), 1-13.

Fenske, M. (2007). Tattoos in American visual culture. New York: Palgrave Macmillan.

Fuchs, P. (1992). Die Erreichbarkeit der Gesellschaft. Zur Konstruktion und Imagination gesellschaftlicher Einheit. Frankfurt a. M.: Suhrkamp.

Fuchs, P. (2004). Das System "Terror". Versuch über eine kommunikative Eskalation der Moderne. Bielefeld: transcript Verlag.

Fuchs, P., \& Heidingsfelder, M. (2004). MUSIC NO MUSIC MUSIC. Zur Unhörbarkeit von Pop. Soziale Systeme, 10(2), 292-324.

Gell, A. (1993). Wrapping in images. Tattooing in Polynesia. Oxford: Claredon Press.

Ginsburg, F. (1995). The parallax effect: The impact of aboriginal media on ethnographic film. Visual Anthropology Review, 11(2), 64-76.

Govenar, A. (2003). Stoney knows how. Life as a sideshow tattoo artist. Atglen: Schiffer Publishing.

Grandy, G., \& Wicks, D. (2008). Competitive advantage as a legitimacy-creating process. Qualitative Research in Organizations and Management: An International Journal, 3(1), 21-41.

Gustafson, M. (2000). The tattoo in the later Roman Empire and beyond. In J. Caplan (Ed.), Written on the body. The tattoo in European and American history (pp. 17-31). London: Reaktion Books.

Heider, F. (2005 [1926]). Ding und Medium. Berlin: Kulturverlag Kadmos.

Hutter, M. (2001). Structural coupling between social systems: Art and the economy as mutual sources of growth. Soziale Systeme, 7(2), 290-313.

Jones, C. P. (2000). Stigma and tattoo. In J. Caplan (Ed.), Written on the body. The tattoo in European and American history (pp. 1-16). London: Reaktion Books.

Kosut, M. (2006). Mad artists and tattooed perverts: Deviant discourse and the social construction of cultural categories. Deviant Behavior, 27(1), 73-95.

la Cour, A., Vallentin, S., Højlund, H., Thyssen, O., \& Rennison, B. (2007). Opening systems theory: A note on the recent special issue of Organization. Organization, 14(6), 929-938.

Laermans, R. (1997). Communication on art, or the work of art as communication? Bourdieu's field analysis compared with Luhmann's systems theory. Canadian Review of Comparative Literature/Revue Canadienne de Littérature Comparée, 24(1), 103-113.

Luhmann, N. (1985). The work of art and the self-reproduction of art. Thesis Eleven, 12(1), 4-27.

Luhmann, N. (1987). The medium of art. Thesis Eleven, 18-19(1), 101-113.

Luhmann, N. (1992). The concept of society. Thesis Eleven, 31(1), 67-80.

Luhmann, N. (1993). Ist Kunst codierbar?, Soziologische Aufklärung 3. Soziales System, Gesellschaft, Organisation, pp. 245-266. Opladen: Westdeutscher Verlag.

Luhmann, N. (1995). The paradoxy of observing systems. Cultural Critique, 31(The politics of systems and environments, part II), 37-55.

Luhmann, N. (1996 [1988]). Die Wirtschaft der Gesellschaft. Frankfurt a. M.: Suhrkamp.

Luhmann, N. (1999). Sign as form. Cybernetics and Human Knowing. A Journal of Second-Order Cybernetics, Autopoiesis and Cyber-Semiotics, 6(3), 21-37.

Luhmann, N. (2000 [1995]). Art as a social system. Stanford: Stanford University Press.

Luhmann, N. (2001 [1997]). Die Gesellschaft der Gesellschaft. Frankfurt a. M.: Suhrkamp.

Luhmann, N. (2002 [1992]). Die Wissenschaft der Gesellschaft. Frankfurt a. M.: Suhrkamp.

Luhmann, N. (2008). Wie lassen sich latente Strukturen beobachten? In P. Watzlawick \& P. Krieg (Eds.), Das Auge des Betrachters. Beiträge zum Konstruktivismus. Festschrift für Heinz von Foerster (pp. 61-74). Heidelberg: Carl-Auer-Systeme Verlag. 
Myers, J. (1992). Nonmainstream body modification. Genital piercing, branding, burning, and cutting. Journal of Contemporary Ethnography, 21(3), 267-306.

Pitts, V. (1999). Body modification, self-mutilation and agency in media accounts of a subculture. Body \& Society, 5(2-3), 291-303.

Pitts, V. (2003). In the flesh. The cultural politics of body modification. New York: Palgrave Macmillan.

Sanders, C. R. (1989). Customizing the body. The art and culture of tattooing. Philadelphia: Temple University Press.

Spencer-Brown, G. (1999 [1969]). Laws of form. Gesetze der Form. Lübeck: Bohmeier Verlag.

Steward, S. M. (1990). Bad boys and tough tattoos. A social history of the tattoo with gangs, sailors, and streetcorner punks 1950-1965. New York/London: The Haworth Press.

Sullivan, N. (2001). Tattooed bodies. Subjectivity, textuality, ethics, and pleasure. Westport: Praeger.

Teubner, G. (1996). Double bind: Hybrid arrangements as de-paradoxifiers. Journal of Institutional and Theoretical Economics, 152(1), 59-64.

The Drawing Center, \& Hardy, D. E. (Eds.) (1995). Pierced hearts and true love. A century of drawings for tattoos. New York/Honolulu: The Drawing Center/Hardy Marks Publications.

van Gulik, W. R. (1982). Irezumi. The pattern of dermatography in Japan. Leiden: E. J. Brill.

Vassileva, S., \& Hristakieva, E. (2007). Medical applications of tattooing. Clinics in Dermatology, 25(4), 367374.

Žižek, S. (2004). The parallax view. New Left Review, 25(January-February), 121-134.

Žižek, S. (2006). The parallax view. Cambridge, Mass./London: The MIT Press.

\section{Notes}

1 This is an abridged version of a chapter of the author's PhD thesis (work in progress). The argument developed here is based on the study of empirical material mainly gathered from qualitative interviews, field observations, tattoo magazines and books. I am grateful to Ivo Mijnssen, Christian Borch, the two anonymous reviewers and the editors for comments and help.

2 I do not suggest conceiving tattooing as a (new) subsystem of its own. Rather, as I will show, the phenomenon works differently and needs to be grasped accordingly. Other (newly described) phenomena, in contrast, have been analysed as subsystems of society (see, e.g., Bohn, 2000; Fuchs \& Heidingsfelder, 2004; and Fuchs, 2004).

3 As Luhmann's own work exemplifies, it may be theoretically and analytically productive to incorporate concepts from other theories (e.g., also the idea of the form/medium distinction inspired by Heider, 2005; see Luhmann, 1987). I agree, therefore, with la Cour, Vallentin, Højlund, Thyssen \& Rennison's (2007) invitation to open up systems theory instead of treating it like a "straitjacket".

4 This is not to say that tattooing and tattoos cannot at all be connected to intimacy, politics and many other social domains. But the point is that one has to distinguish between the way tattooing and tattoos emerge (e.g., through economic and artistic communication) and the way they are described (e.g., the motivations to get a particular tattoo) or how tattoos communicate visually (political, intimate, lifestyle etc. "statements").

5 This is not the place to discuss the concept of parallax in regard to potentially similar concepts in systems theory (structural coupling, "Mehrsystemereignis", or hybrids; see, e.g., Luhmann, 1992, 2002, p. 32; Teubner, 1996). 
6 A tattooist talking about his career start describes the situation as follows: "Since we were all punk rock and broke, my rate of charge was based on food and alcohol. A small tattoo would cost you a bag of Doritos and a half-liter of chocolate milk; a medium-sized tattoo would run you a deli style sandwich; and a large tattoo would set you back a case of beer" (in the tattoo periodical Prick Magazine, 2008, 8 (5), p. 52 , http://www.prickmag.net/prick_february2008.html).

7 In this respect, one can see the tattoo as a structural coupling of economy and art (see Hutter, 2001).

8 Such an operational conceptualisation of art, that is, communication through art, differs from other theoretical suggestions that see art as communication about art (e.g., Sanders, 1989; on the difference between Luhmann and Bourdieu, see Laermans, 1997).

9 The tattoo can also emerge as an artistic medium in the context of art on paper and canvas (on exhibitions of such artwork, see, The Drawing Center \& Hardy, 1995; Kosut, 2006). In such cases, however, it is not tattooing that forms it but drawing and painting.

Christian Wymann

Lecturer, Lic.phil.

Department of Sociology

University of Basel, Switzerland

christian.wymann@unibas.ch

and

PhD student

Department of Management, Politics and Philosophy Copenhagen Business School, Denmark 